Sigma Teknika, Vol.2, No.2 : 158-172

November 2019

E-ISSN 2599-0616

P ISSN 2614-5979

\title{
RANCANG BANGUN TEXT DAN ANIMASI 3 DIMENSI PADA LED CUBE BERBASIS ARDUINO UNO ATMEGA 328 \\ Muhammad Iqbal ${ }^{1}$, Reza Nandika ${ }^{2}$, Endang Susanti $^{3}$ \\ ${ }^{1,2,3)}$ Teknik Elektro, Fakultas Teknik, Universitas Riau Kepuluan Batam Email: telechaty300596@gmail.com
}

\begin{abstract}
Promotion is one means to increase sales figures at a company. And the product being promoted. Promotions carried out to potential target markets. There are various kinds of promotional media used such as neon boxes. Neon Box requires neon lights with high electric power and high prices. On the other hand the neon box image is static or cannot be changed. So from the problems above, through this study the authors designed a promotional media using LEDs that were shaped like cubes. Because LED prices are not expensive. This promotional tool was built using an Arduinobased microcontroller and connected to the interface on the desktop. Display that can be arranged through the desktop are letters, numbers, and shapes (flat areas). CUBE LEDs were tested 5 times for each flame pattern and the test results were obtained successfully. So the CUBE LED was successfully designed and built and found no errors.
\end{abstract}

Keywords: LED cube, promotional media, Light Emitting Diode

\begin{abstract}
Abstrak
Media promosi merupakan salah satu sarana untuk menaikannya angka penjualan pada suatu perusahaan. Dan produk yang dipromosikan. Promosi yang dilakukan sampai kepada target pasar yang potensial. Ada berbagai macam media promosi yang digunakan misalnya neon box. Neon Box membutuhkan lampu neon dengan daya listrik yang tinggi dan harga mahal. Disisi lain gambar neon box bersifat statis atau tidak bisa diganti-ganti. Maka dari permasalahan diatas, melalui penelitian ini penulis merancang media promosi menggunakan LED yang dibentuk menyerupai kubus. Karena harga $L E D$ yang tidak mahal. Alat bantu promosi ini dibangun menggunakan mikrokontroller berbasis Arduino dan dihubungkan dengan Interface yang ada di desktop. Tampilan yang bisa diatur melalui desktop yaitu huruf, angka, dan bentuk (bidang datar). LED CUBE dilakukan pengujian sebanyak 5 kali untuk setiap pola nyalanya dan dari hasil pengujian didapatkan berhasil. Jadi $L E D$ CUBE berhasil dirancang dan dibangun dan tidak didapati error.
\end{abstract}

Kata Kunci: LED cube, media promosi, Light Emitting Diode 
Sigma Teknika, Vol.2, No.2 : 158-172

November 2019

E-ISSN 2599-0616

P ISSN 2614-5979

\section{PENDAHULUAN}

Perkembangan teknologi visual sangat pesat sejak ditemukannya teknologi $L E D$ yang sudah diterapkan dalam berbagai media elektronik. Banyak pengusaha yang menggunakan LED ini sebagai sarana promosi agar para konsumen tertarik dan berminat untuk datang ke toko mereka. Running Text, LED Bill Board, Layar $L E D T V$, dan lain-lain sekarang banyak menggunakan teknologi LED. Dengan bantuan mikrokontroler dapat menghasilkan tampilan yang sangat indah dan dapat di manfaatkan sebagai sarana informasi, hiburan dan masih banyak lagi.

Cara pembuatan dan penggunaan Persistence of Vision berkembang dengan pesat, tetapi seringkali hanya dapat menampilkan suatu tampilan yang monoton dan tidak banyak pilihan. Dalam hal ini, persistence of vision dimunculkan oleh barisan LED blue yang tersusun rapi berbentuk kubus dan dicontrol oleh arduino uno yang berfungsi sebagai pengendali tiap $L E D$. Dengan bentuk seperti ini, hasil yang akan di tampilkan dapat berbentuk 3D.

Berdasarkan uraian di atas, maka penulis ingin mendesain program animasi dan teks dengan menggunakan prinsip POV dan dengan bantuan arduino uno sehingga tampilan yang akan dihasilkan sesuai dengan yang pengguna inginkan.

\section{LANDASAN TEORI}

Saat ini teknologi sangatlah maju dan seolah telah menjadi bagian tak terpisahkan dari kehidupan manusia. Teknologi dalam bidang elektronik adalah teknologi paling meningkat dibanding bidang lain. Salah satu bidang yang banyak memakai teknologi elektronika adalah bidang hiburan. Berbagai macam hiburan mulai dari televisi , radio, video game dan berbagai macam hiburan lainnya bisa dipastikan memakai teknologi elektronik di dalamnya. Namun tidak menuntut kemungkinan juga ketika bidang teknologi diterapkan untuk meningkatkan kualitas dunia Pendidikan.

LED cube adalah susunan dari beberapa lampu $L E D$ yang di bentuk kotak meyerupai kubus dan berbagai ragam skala. LED cube adalah pengembangan dari dot matrik. Perbedaan utamanya adalah $L E D$ cube mampu menampilkan pola dalam bentuk 3 dimensi . Pola dihasilkan dari hasil coding Menggunakan Bahasa $\mathrm{C}$ pada program Arduino. Oleh karena itu, penulis memiliki gagasan untuk membuat sebuah produk 
Sigma Teknika, Vol.2, No.2 : 158-172

November 2019

E-ISSN 2599-0616

P ISSN 2614-5979

berupa $L E D$ cube tersebut nantinya dapat diterapkan dalam dunia industry. Untuk pemanfaatan teknologi ini akan difokuskan hanya untuk memperkenalkan bangun ruang kubus. Pengenalan bangun ruang yang berupa titik sudut, rusuk sudut, sisi dan semua bagian dari kubus. Pembelajaran yang akan diterapkan adalah menyalakan $L E D$ sesuai dengan bagian kubus yang akan diperkenalkan. Pengontrolan pola nyala $L E D$ akan diatur menggunakan Arduino Uno.

\section{A. Landasan Teori}

Landasan teori menjelaskan secara lebih spesifik lagi mengenai aspek-aspek yang terkait dalam perancangan $L E D$ cube berbasis arduino ini. Dalam penulisan yang dilakukan pada landasan teori didapt dari buku-buku dan jurnal penelitian sebagai referensi dalam perancangan alat yang dilakukan.

\section{B. Pengertian $L E D$}

LED adalah komponen elektronika yang dapat memancarkan cahaya monokromatik ketika diberikan tegangan maju. LED merupakan keluarga Dioda yang terbuat dari bahan semikonduktor. Warna-warna Cahaya yang dipancarkan oleh $L E D$ tergantung pada jenis bahan semikonduktor yang dipergunakannya.
Cara kerja $L E D$ hanya akan memancarkan cahaya apabila dialiri tegangan maju (bias forward) dari Anoda menuju ke Katoda. Saat Elektron berjumpa dengan Hole akan melepaskan photon dan memancarkan cahaya monokromatik (satu warna).

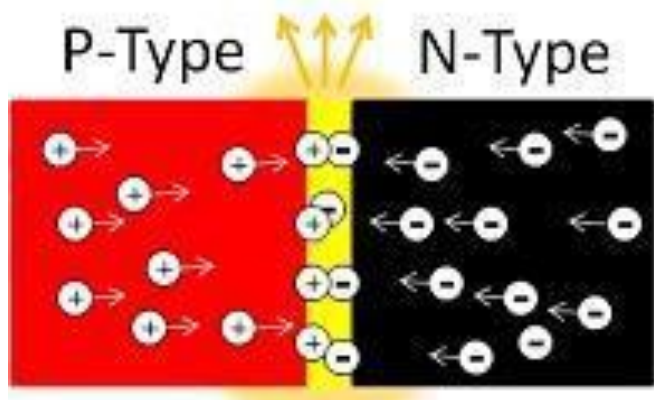

Gambar 2.1 Type $\mathrm{P}$ dan Type $\mathrm{N}$ pada LED

\section{Arduino}

Arduino didefinisikan sebagai sebuah platform elektronik yang open source, berbasis pada software dan hardware yang fleksibel dan mudah digunakan, yang ditujukan untuk seniman, desainer, hobbies dan setiap orang yang tertarik dalam membuat obyek atau lingkungan yang interaktif .

Arduino sebagai sebuah platform komputasi fisik (Physical Computing) yang open source pada board input ouput sederhana, yang dimaksud dengan platform komputasi fisik disini adalah sebuah sistem fisik yang interaktif dengan penggunaan software dan 
Sigma Teknika, Vol.2, No.2 : 158-172

November 2019

E-ISSN 2599-0616

P ISSN 2614-5979

hardware yang dapat mendeteksi dan merespons situasi dan kondisi.

\section{Software Arduino}

Software Arduino adalah sebuah integrated development environment (IDE) yang sangat canggih ditulis dengan menggunakan bahasa java sehingga tidak perlu diinstal seperti software pada umumnya tapi dapat langsung dijalankan selama komputer yang digunakan sudah terinstal java runtime .

Saat ini Arduino sangat popular di seluruh dunia. Banyak pemula yang belajar mengenal robotika dan elektronika lewat Arduino karena mudah dipelajari . tapi tidak hanya pemula , para hobbyist atau professional pun ikut senang mengembangkan aplikasi elektronik menggunakan Arduino. Bahasa yang dipakai dalam Arduino bukan assembler yang relative sulit, tetapi Bahasa $\mathrm{C}$ yang disederhanakan dengan bantuan pustaka-pustaka (libraries) Arduino.

\section{E. Arduino Uno R3}

Arduino uno R3 adalah papan pengembangan (development board) mikrokontroler yang berbasis chip ATmega 328P. Disebut sebagai papan pengembangan karena board ini memang berfungsi sebgai arena prototyping sirkuit mikrokontroler, dengan menggunakan

papan pengembangan anda akan lebih mudah merangkai rangkaian elektronika mikrokontroler dibanding jika anda memulai merakit ATMega328 dari awal di breadboard.

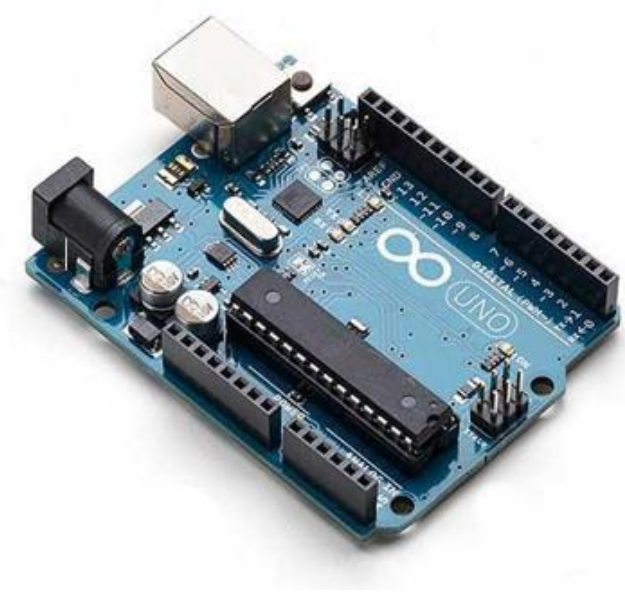

Gambar 2.3 Arduino Uno R3

\section{METODE PENELITIAN}

\section{A. Alat dan Bahan}

Metode penelitian yang dinilai sesusai dengan pelaksanaan penelitian tugas akhir ini adalah metode kualitatif, penyusunan skripsi ini didasarkan pada masalah yang dirumuskan sebelum-sebelumnya yang nantinya diwujudkan dalam bentuk simulasi perancangan alat, data dan spesifikasi komponen yang digunakan dalam perancangan alat adalah data sekunder dari 
referensi buku dan internet dan metode lain yang digunakan. Selanjutnya pelaksanaannya akan dibagi melalui beberapa tahapan.

Dalam perancangan LED cube berbasis arduino uno, dibutuhkan alat dan bahan sebagai pendukung penelitian. Pengunaan alat dan bahan yang tepat dan baik akan mempermudah pengerjaan pada perancangan alat. Adapun alat dan bahan yang digunakan:

\section{B. Alur Penelitian}

Dalam Perancangan yang dilakukan harus memiliki alur penelitian atau yang biasa disebut dengan flow chart. Hal ini dimaksudkan agar sistem kerja alat dapat dipahami dengan mudah melalui alur kerjanya dari awal start hingga finish, dan karena hal tersebut penelitian mengenai perancangan LED cube berbasis arduino uno ini juga memiliki sebuah flow chart.

Pada penelitian dan perancangan memiliki pendekatan sistem berurutan, yaitu analisis kebutuhan, desain, proses ( pengkodean), dan pengujian.

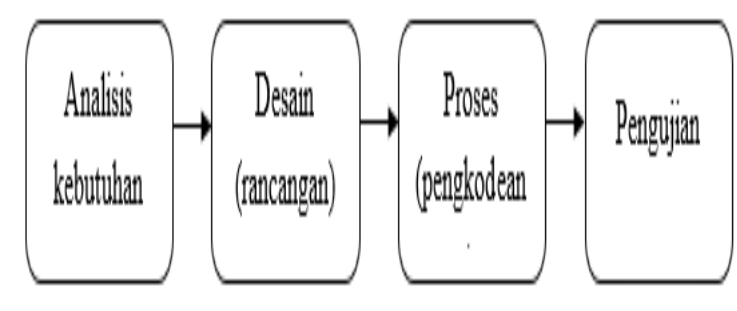

Gambar 3.1 Sistem Penelitian

Sehingga dari setiap langkah yang dilakukan dapat menghasilkan struktur kerja yang mudah dipahamin dari setiap langkah yang telah disusun. Perancangan perangkat harus menggunakan pendekatan dan proses yang berurutan seperti analisis kebutuhan yang digunakan, perancangan sistem yang digunakan untuk pemecahan masalah, pengaplikasian perancangan serta proses pengujian yang akan memenntukan akhir dari sebuah perancangan. 
Sigma Teknika, Vol.2, No.2 : 158-172

November 2019

E-ISSN 2599-0616

P ISSN 2614-5979
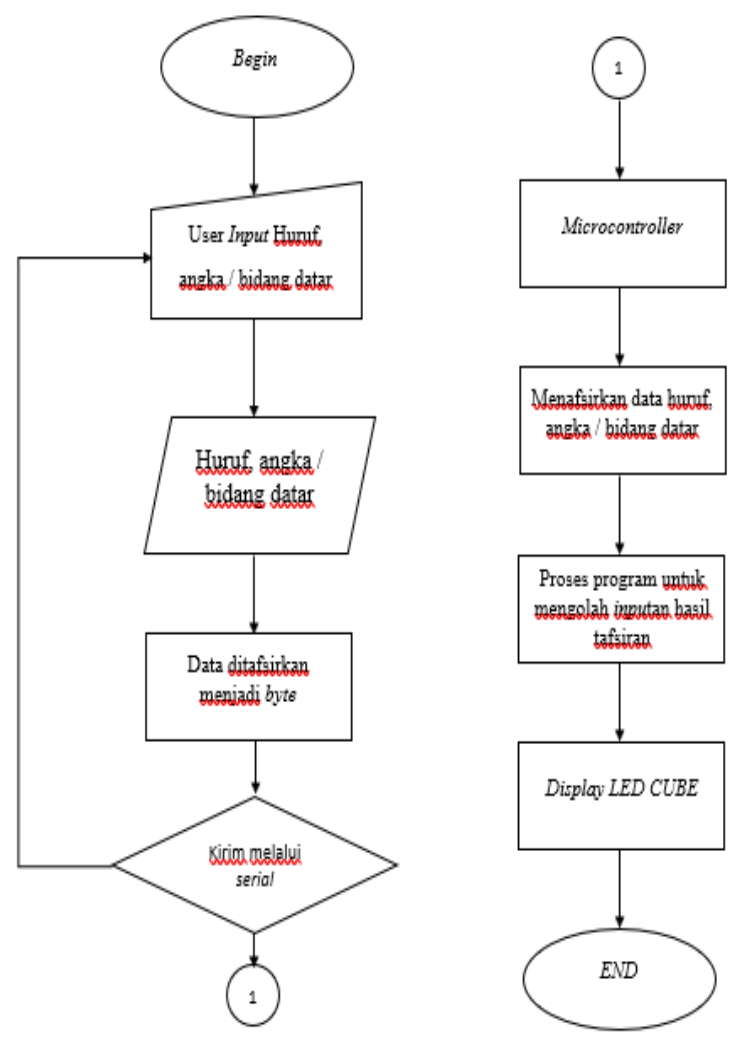

Gambar 3.2 Diagram Alir Penginputan

Program

User mengirim kalimat berupa huruf, angka atau symbol yang nantinya akan diterjemahkan oleh Arduino ke dalam binary code. Dan akan ditampilkan kembali dalam nyala lampu yang berbentuk huruf, angka atau symbol tersebut. Untuk sekarang jika mau mengubah kalimat yang akan dikirim maka harus upload code baru ke dalam arduino.

\section{Perancangan Sistem}

Perancangan LED cube ini menggunakan arduino uno sebagai mikrokontrollernya. Perancangan ini terdiri dari dua bagian utama, yaitu sistem perancangan perangkat keras (hardware) dan sistem perancangan perangkat lunak (software). Perancangan perangkat keras terdiri dari rangkaian minimum mikrokontroler, rangkaian catudaya, dan rangakaian penerima. Perangakat keras mencakup seluruh bagian perancangan dari seluruh LED cube. Sementara perancangan perangkat lunak (software) menggunakan IDE (Integrated Development Environment). Menerapkan setiap langkah yang dibutuhkan untuk menggerakaan bagian - bagian dari LED cube dengan program yang disimpan didalam arduino.

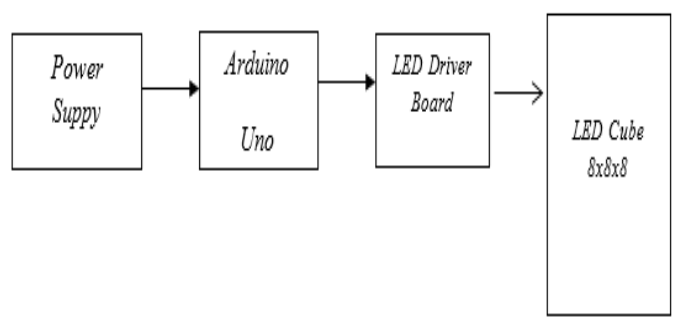

\section{Proses pembuatan}

Pada proses pembuatan $L E D$ kubus tersebut dibagi menjadi beberapa bagian seperti bagian hardware dan software. Desain 
Sigma Teknika, Vol.2, No.2 : 158-172

November 2019

E-ISSN 2599-0616

P ISSN 2614-5979

Hardware dan Software meliputi dengan hal sebagai berikut :

1. Hardware yang pertama berguna untuk menerima input dan mengeluarkan output pada hardware LED. Hardware ini berupa rangkaian driver $L E D$ yang berfungsi sebagai mengolah data input dari Arduino dan akan dikirim ke rangkaian $L E D$ cube

2. Hardware yang kedua berupa susunan matrik kubus $L E D$, kubus $L E D$ tersusun dari $L E D$ yang dirangkaian sedemikian rupa sehingga berbentuk bangun kubus

3. Sofware yang digunakan yaitu Arduino Uno Atmega 328 , yang berfungsi sebagai aplikasi Bahasa $\mathrm{C}++$ untuk menginput program ke dalam rangkaian driver $L E D$ dan akan menampilkan hasil coding di kubus LED.

\section{E. Pengujian dan Pengambilan Data}

Untuk mengetahui kinerja dari sebuah alat yang di rancang, maka dilakukan pengujian pada alat tersebut. Dari pengujian tersebut akan ditarik data untuk kemudian dilakukan analisa dan perbandingan agar dapat menarik kesimpulan dari tujuan penelitian. Dalam perancangan $L E D$ cube berbasis arduino uno ini pengujian dilakukan dalam beberapa skema pengujian berdasarkan apa yang ada didalam tujuan penelitian. Bagian-bagian pengujian tersebut yaitu .

\section{F. Pengujian Kondisi LED}

Pada pengujian akhir dari $L E D$ cube adalah dengan menguji setiap bagian dari LED cube dapat berjalan dengan baik atau tidak. Pengujian meliputi koneksi dari kontrol $L E D$ cube, hasil coding pada program sesuai dengan yang dihasilkan pada tampilan $L E D$ cube.

\section{G. Pengujian Software}

Pengujian software ini bertujuan untuk memastikan bahwa Led Cube 8x8x8 ini dapat diprogram dan kita dapat menampilkan tampilan sesuai yang diinginkan. Dalam pengujian software ini, dengan menggunakan arduino uno sebagai pengendali tiap led dan mengunakan bahasa khusus arduino uno.

\section{HASIL DAN PEMBAHASAN}

Menjelaskan tentang hasil dan pembahasan yang telah didapatkan pada pengujian alat yaitu rancang bangun text dan animasi 3 dimensi pada LED cube berbasis Arduino uno Atmega 328, dan didalammya juga akan dijabarkan pengujian yang terjadi dan didapat pada proses pengujian alat 
Sigma Teknika, Vol.2, No.2 : 158-172

November 2019

E-ISSN 2599-0616

P ISSN 2614-5979

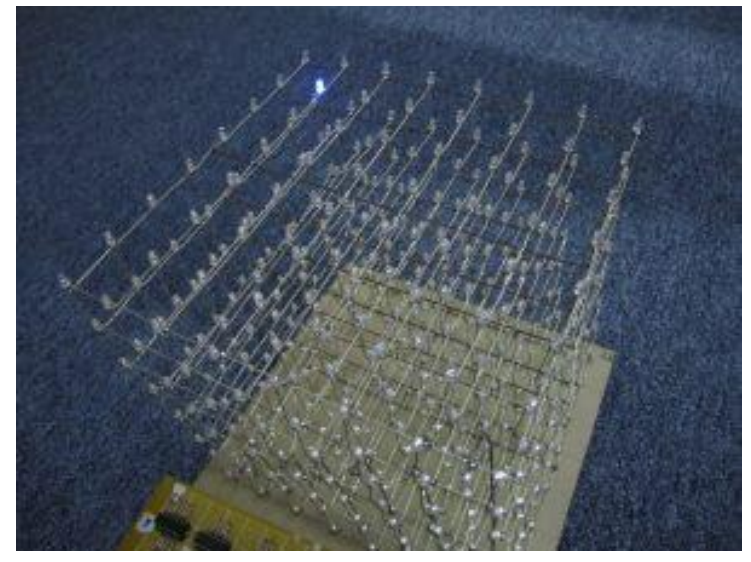

Gambar

Pada langkah pertama pengujian yang dilakukan yaitu mencoba $L E D$ satu persatu agar disaat pemasangan $L E D$ tidak dalam kondisi rusak.

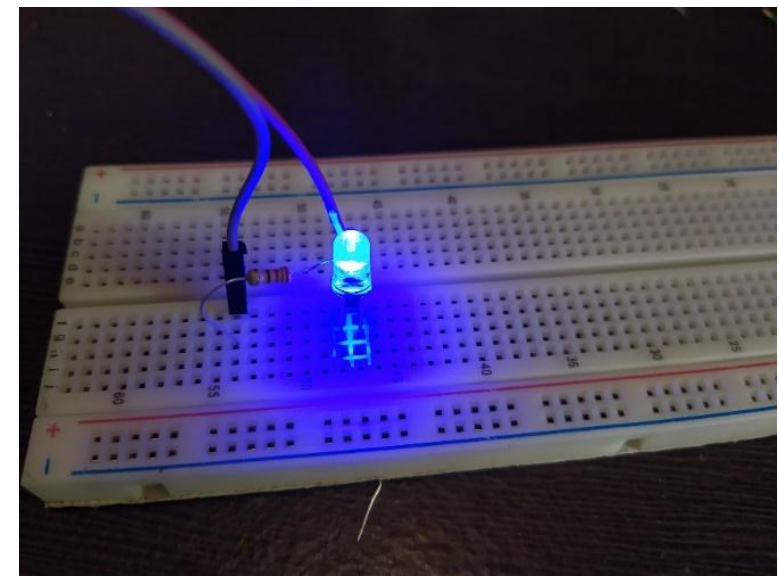

Gambar 4.2 Pengujian LED

Setelah $L E D$ diuji satu persatu lalu disusun sesuai susunan $L E D$ pada layer yang telah digambarkan pada bab sebelumnya . Dan layer $L E D$ disusun menyerupai bentuk kubus

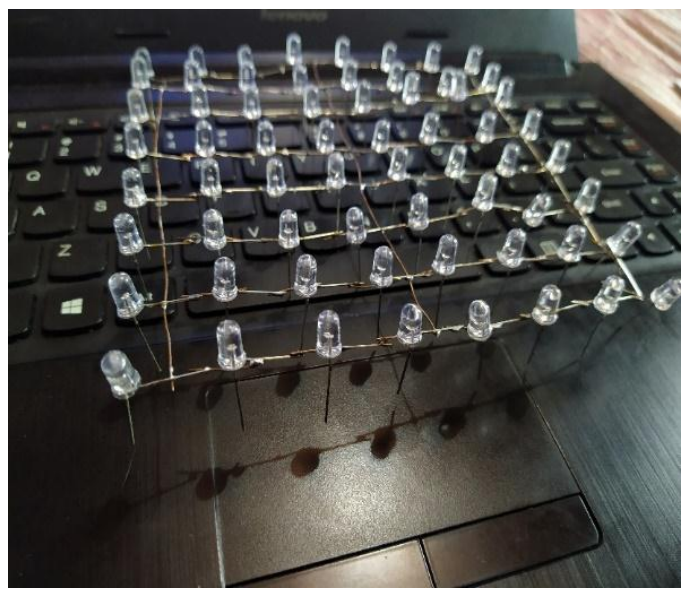

Gambar 4.3 Susunan Layer LED

Pengujian selanjutnya dilakukan dengan cara menghidupkan kubus LED agar dapat

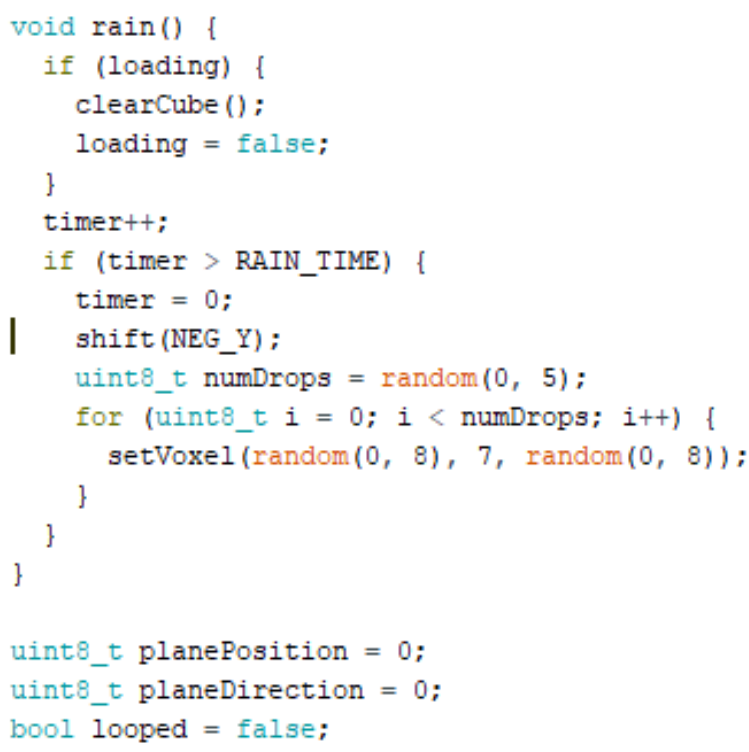

mengetahui jika ada kerusakan atau mati 
Sigma Teknika, Vol.2, No.2 : 158-172

November 2019

E-ISSN 2599-0616

P ISSN 2614-5979

pada $L E D$ pada saat penyolderan terjadi.

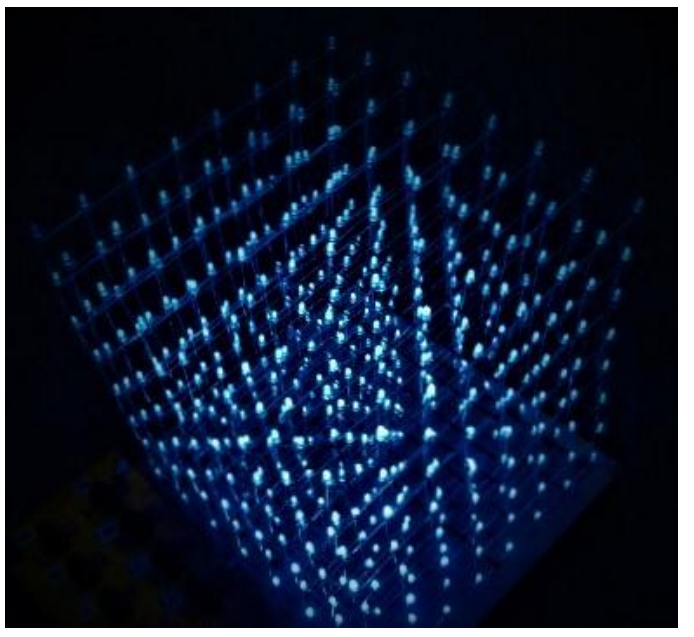

Gambar 4.4 Lampu LED

\section{A. Pengujian Pola Obyek}

Pada pengujian selanjutnya akan LED cube akan diprogram dan diuji apakah program yang kita buat sesuai dengan hasil yang akan di tampilkan, hasil dari pengujian akan di tampilkan list program dan tampilan pada LED cube.

\section{B. Pengujian animasi Rain}

Pada pengujian animasi rain ini, Arduino mengirimkan nilai ke driver LED dan secara otomatis Arduino meng-eksekusi program seperti pada gambar berikut ini .

\section{Gambar 4.5 List program Rain}

Pada program tersebut LED cube akan menampilkan titik-titik lampu secara bergantian sesuai dengan program yang diterima dan hasilnya seperti gambar berikut.

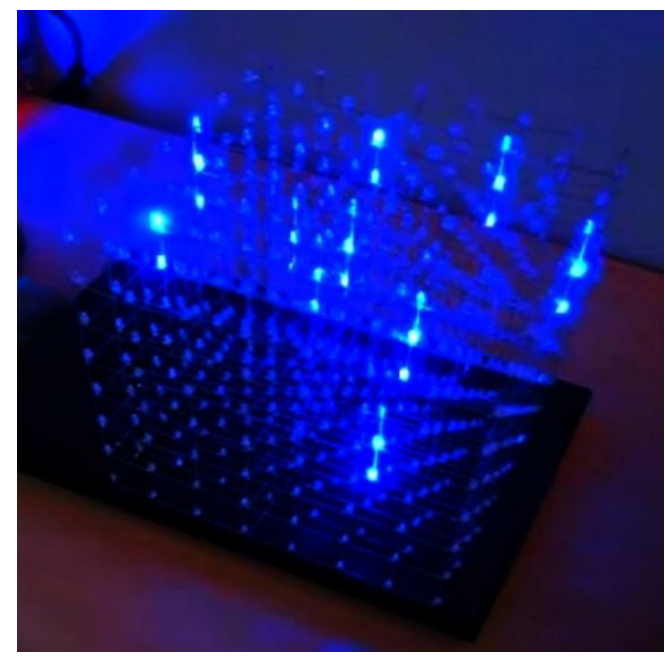

Gambar 4.6 Pola Rain

\section{Pengujian animasi Sendvoxel}

Pada pengujian animasi sendvoxel Arduino mengirimkan nilai ke driver LED dan secara otomatis Arduino meng-eksekusi program seperti pada gambar berikut ini . 
Sigma Teknika, Vol.2, No.2 : 158-172

November 2019

E-ISSN 2599-0616

P ISSN 2614-5979

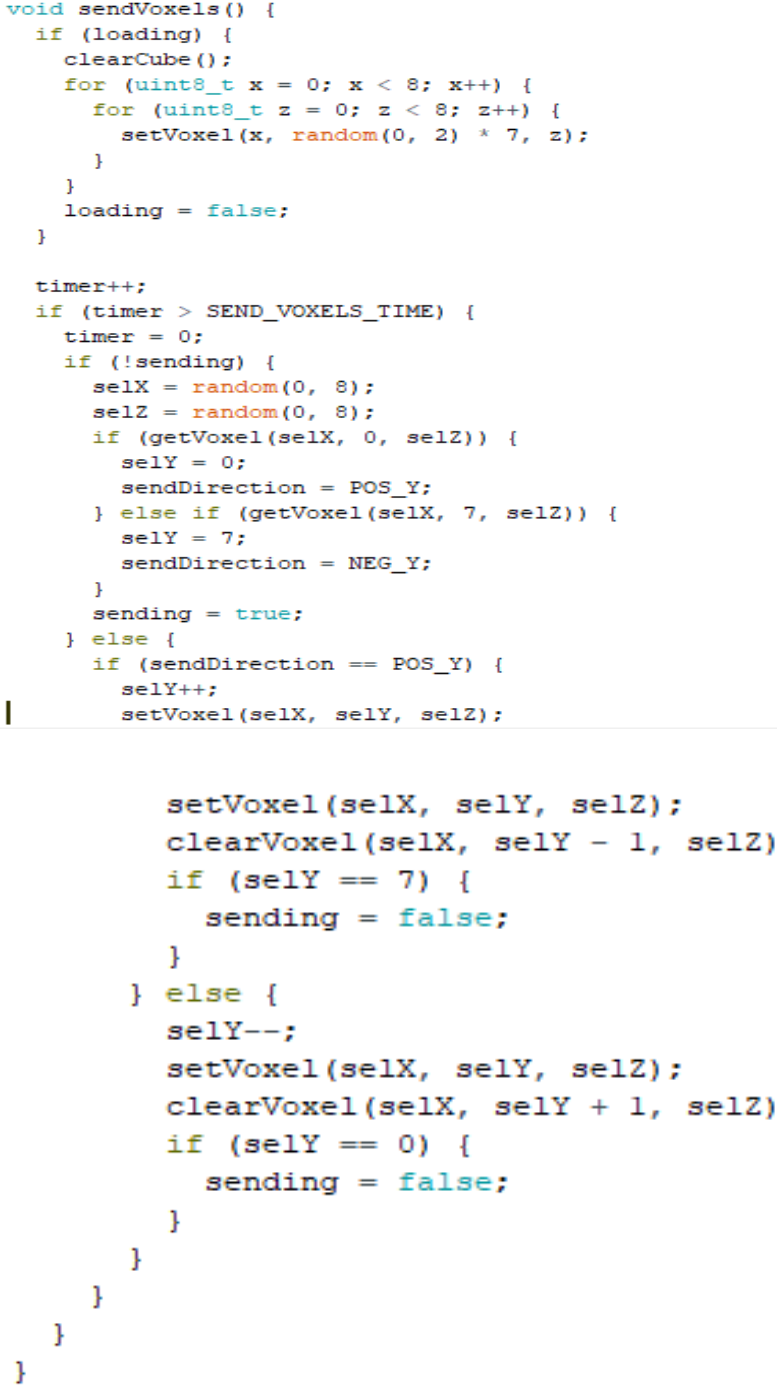

Gambar 4.7 List program Sendvoxel

Pada program tersebut LED cube akan menghidupkan semua LED pada layer paling atas dan LED satu persatu akan jatuh sehingga layer paling bawah hidup sesuai kolom di atasnya . 
Sigma Teknika, Vol.2, No.2 : 158-172

November 2019

E-ISSN 2599-0616

P ISSN 2614-5979

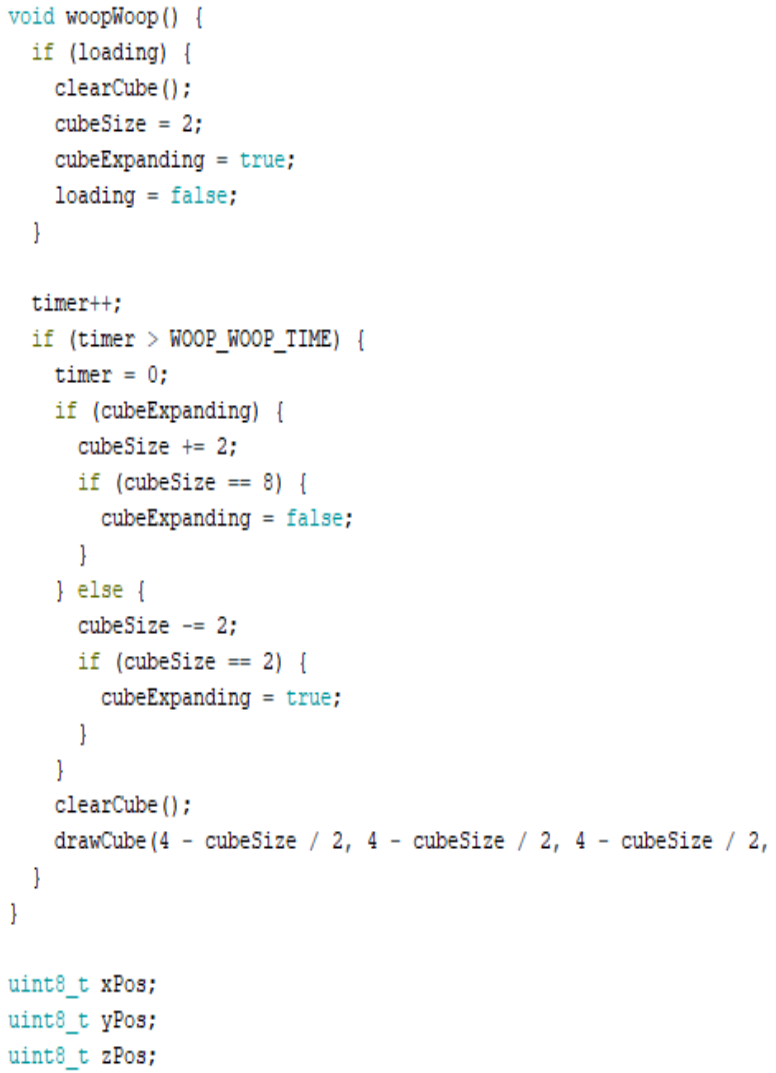

Gambar 4.9 List program woopwoop

Pada program tersebut LED cube akan menyala dari sudut LED cube berbentuk seperti kubus kecil dan akan membesar mengikuti bentuk kubus yang dibuat lalu berpindah ke sudut lain nya secara terus menerus.

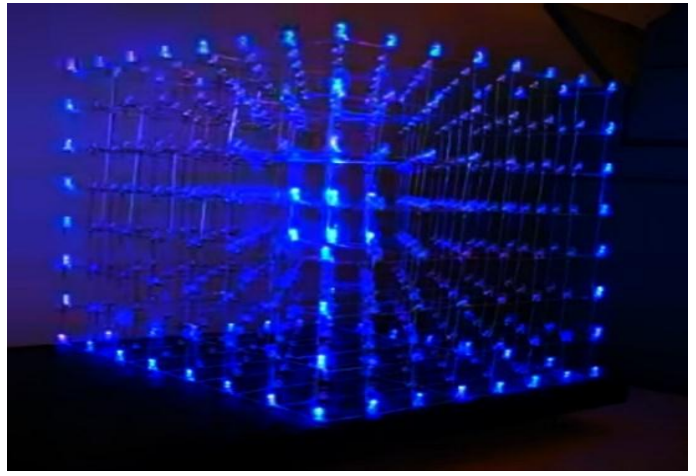

Gambar 4.10 Pola woopwoop

\subsubsection{Pengujian animasi planeboing}

Pada pengujian animasi planeboing Arduino secara otomatis Arduino meng-eksekusi program seperti pada gambar berikut ini .

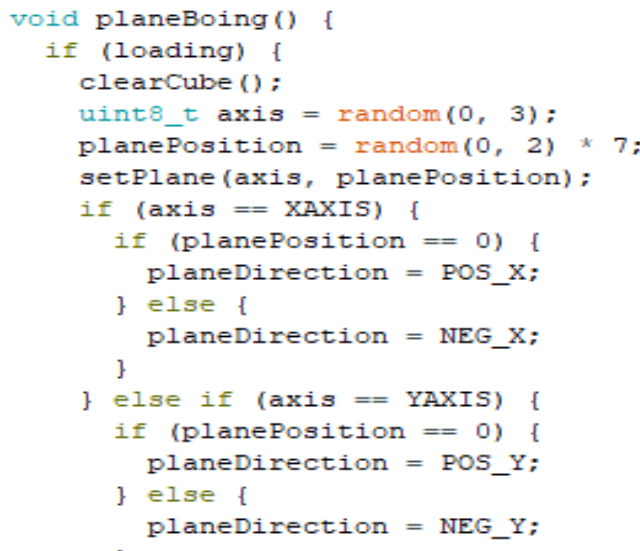

Gambar 4.11 List program plane boing 
Sigma Teknika, Vol.2, No.2 : 158-172

November 2019

E-ISSN 2599-0616

P ISSN 2614-5979

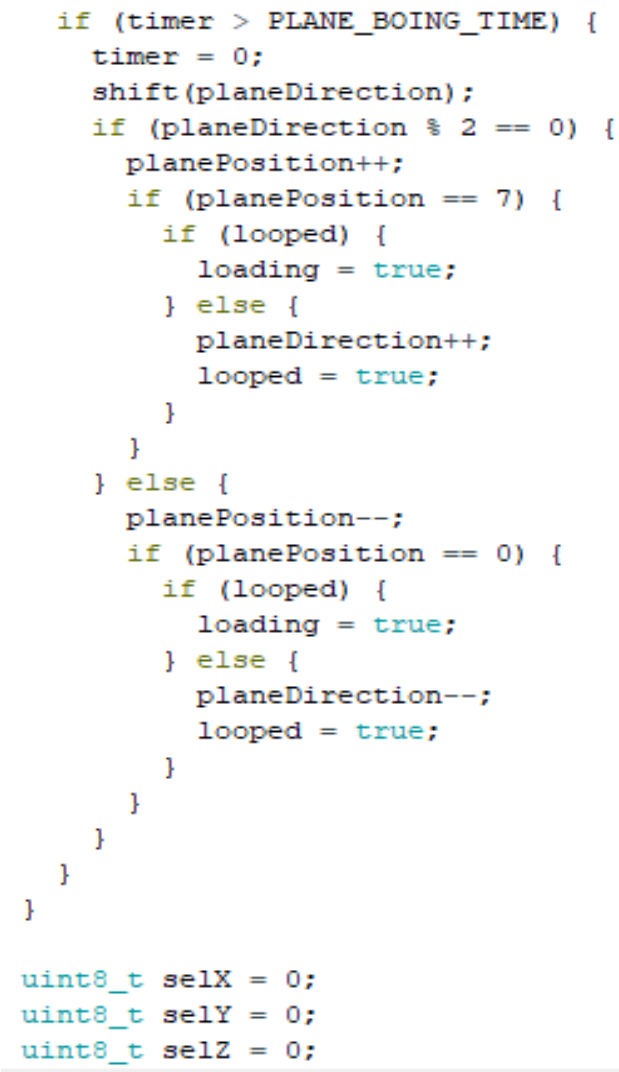

Gambar 4.12 List program planeboing

Pada program tersebut LED cube layer paling bawah akan menyala membentuk persegi dan akan berpindah pindah mengikuti urutan layer yang ada.

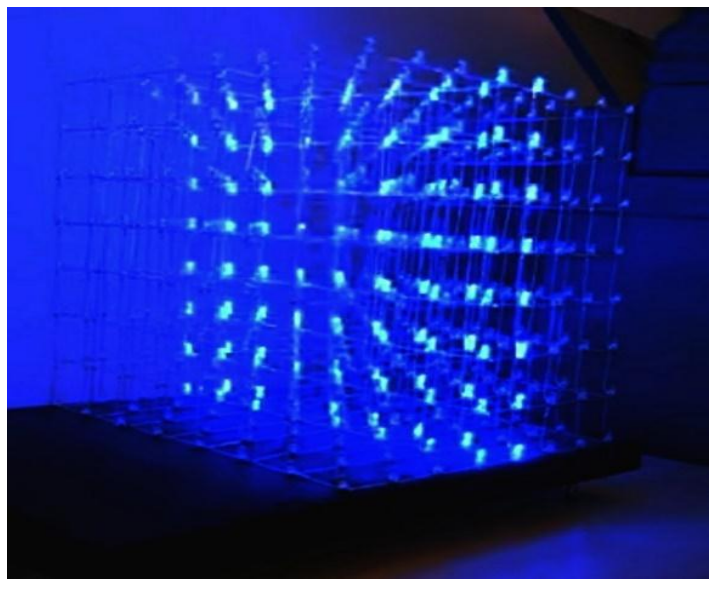

Gambar Pola PlaneBoing

\section{KESIMPULAN DAN SARAN}

\section{A. Kesimpulan}

Kesimpulan yang dapat diambil dari perancangan bangun text dan animasi dimensi pada $L E D$ cube berbasis Arduino uno atmega 328 :

1. Dalam pembuatan LED cube $8 \times 8 \times 8$ diperlukan beberapa tahap pembuatan, pertama pembuatan hardware yang berupa susunan IC, Transistor, Resistor dan komponen pendukung lainnya dalam pembuatan LED cube. Kedua yaitu software berupa coding yang terdapat dalam Arduino yang telah dibuat untuk menjalankan rangkaian LED berbentuk kubus.

2. Pada led cube ada 6 macam yang ditampilkan, yaitu : rain, plane boing, woopwoop, cube jump, glow, text / number. 
Sigma Teknika, Vol.2, No.2 : 158-172

November 2019

E-ISSN 2599-0616

P ISSN 2614-5979

Animasi tersebut dikirim datanya melalui

2015. Smart LED cube $5 \times 5 \times 5$

Arduino, lalu data yang telah dibuat akan diinput pada driver LED cube agar diproses dan ditampilkan di kubus LED agar dapat diketahui hasil coding sesuai dengan yang dibuat pada Arduino atau tidak.

\section{B. Saran}

Saran yang dapat diberikan untuk pengembangan perancangan alat ini selanjutnya adalah sebagai berikut :

1. Untuk pengembangan diharapkan agar desain animasi 3 dimensi dan text lebih banyak variasinya dan lebih mudah untuk diaplikasikan.

2. Untuk pengembangan alat, diharapkan agar menggunakan lampu led RGB (Red, Green, Blue) agar tampilan animasi 3 dimensi dan text berjalan lebih indah dilihat, sehingga lebih menarik dalam mempromosikan suatu produk.

\section{DAFTAR PUSTAKA}

[1]. . Adisty Hanny Asri . 2014 .

Pengenalan Elektronika Dan

Komponen Dasar Elektronika .

Bandung

[2]. Annisa Rizqi Nurlailiyah, Aulia

Oktaviana, Ninda Putri Anandita .

menggunakan Arduino Uno Dan

Potensiometer. Semarang.

[3]. Lawung Citra Yudha Iswara . 2017.

Sistem Pengatur Running Text

Menggunakan Android Dengan

Interface Bluetooth Berbasis Arduino.

Ponorogo

[4]. Lilik Hari Santoso, Rita Rosita. 2017 .

Rancang Bangun Papan Infromasi

Runnig Text Berbasis Arduino Uno Di

STT TEXMACO. Subang.

[5]. Michael Hans . 2016. Rancang

Bangun LED Cube Sebagai Alat Bantu

Media Promosi. Surabaya.

[6]. Sagita Mella. 2015 . Aplikasi LED

RGB Pada Lengan Robot Penyortir

Kotak Berdasarkan Warna Berbasis

Arduino Uno. 